\title{
Article
}

\section{Mapping the solid-state properties of crystalline lysozyme during pharmaceutical unit-operations}

Mohammad, Mohammad Amin, Grimsey, Ian M. and Forbes, Robert Thomas

Available at http://clok.uclan.ac.uk/13509/

Mohammad, Mohammad Amin, Grimsey, lan M. and Forbes, Robert Thomas ORCID: 0000-0003-3521-4386 (2015) Mapping the solid-state properties of crystalline lysozyme during pharmaceutical unit-operations. Journal of Pharmaceutical and Biomedical Analysis, 114 . pp. 176-183. ISSN 0731-7085

It is advisable to refer to the publisher's version if you intend to cite from the work. http://dx.doi.org/10.1016/j.jpba.2015.05.011

For more information about UCLan's research in this area go to http://www.uclan.ac.uk/researchgroups/ and search for <name of research Group>.

For information about Research generally at UCLan please go to http://www.uclan.ac.uk/research/

All outputs in CLoK are protected by Intellectual Property Rights law, including Copyright law. Copyright, IPR and Moral Rights for the works on this site are retained by the individual authors and/or other copyright owners. Terms and conditions for use of this material are defined in the policies page.

\section{CLoK}

Central Lancashire online Knowledge www.clok.uclan.ac.uk

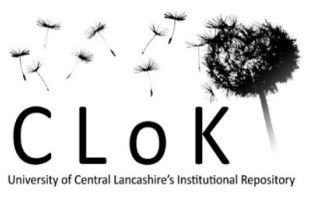




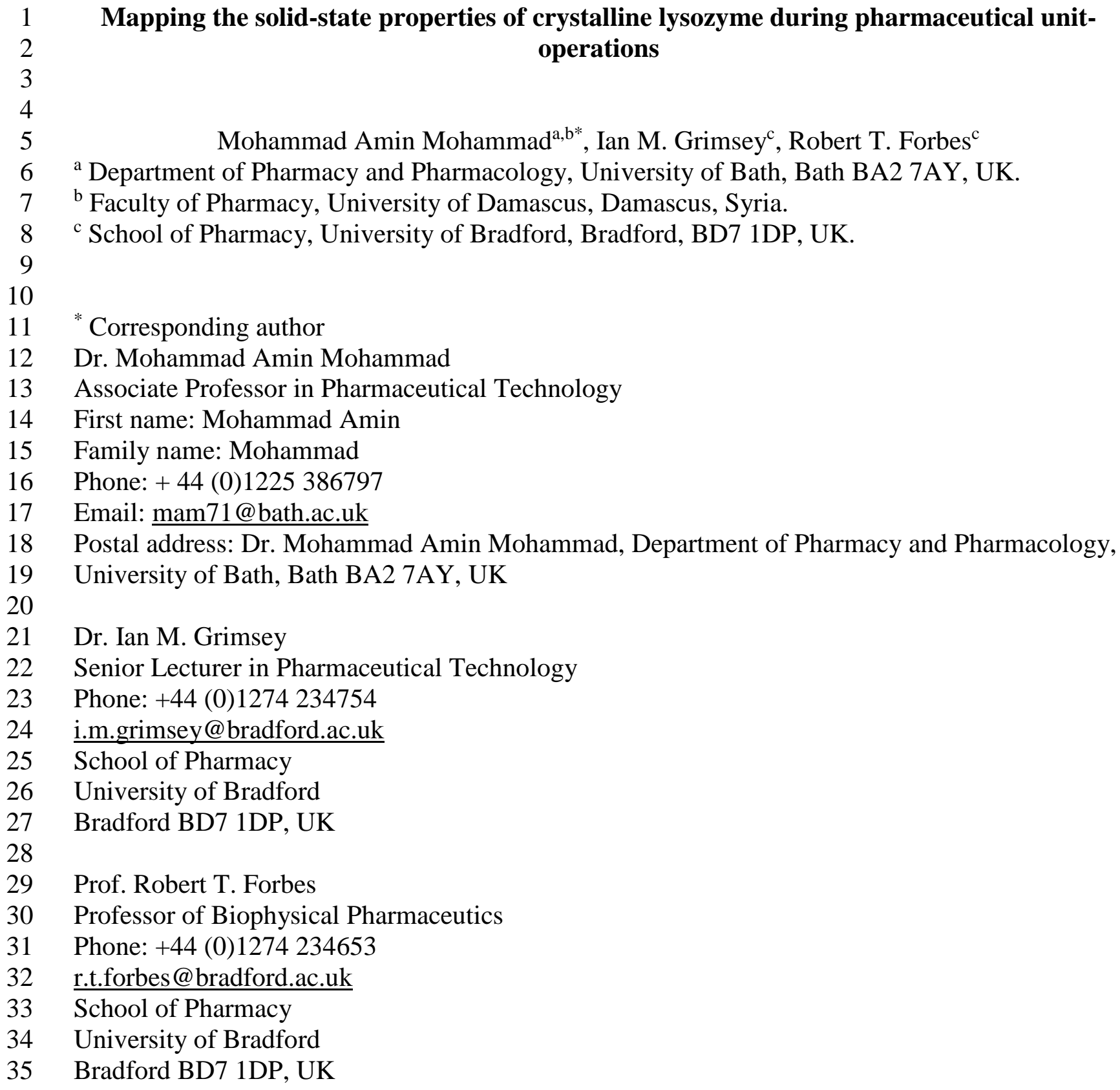

Dr. Ian M. Grimsey

Senior Lecturer in Pharmaceutical Technology

Phone: +44 (0)1274 234754

i.m.grimsey@bradford.ac.uk

School of Pharmacy

University of Bradford

Bradford BD7 1DP, UK

Prof. Robert T. Forbes

Professor of Biophysical Pharmaceutics

Phone: +44 (0)1274 234653

r.t.forbes@bradford.ac.uk

School of Pharmacy

University of Bradford

Bradford BD7 1DP, UK 


\section{Abstract}

47 Bulk crystallisation of protein therapeutic molecules towards their controlled drug delivery is of

48 interest to the biopharmaceutical industry. The complexity of biotherapeutic molecules is likely to

49 lead to complex material properties of crystals in the solid state and to complex transitions. This

50 complexity is explored using batch crystallised lysozyme as a model. The effects of drying and

51 milling on the solid-state transformations of lysozyme crystals were monitored using differential

52 scanning calorimetry (DSC), X-ray powder diffraction (XRPD), FT-Raman, and enzymatic assay.

53 XRPD was used to characterise crystallinity and these data supported those of crystalline lysozyme

54 which gave a distinctive DSC thermogram. The apparent denaturation temperature $\left(T_{m}\right)$ of the

55 amorphous lysozyme was $\sim 201{ }^{\circ} \mathrm{C}$, while the $\mathrm{T}_{\mathrm{m}}$ of the crystalline form was $\sim 187{ }^{\circ} \mathrm{C}$. Raman

56 spectra supported a more $\alpha$-helix rich structure of crystalline lysozyme. This structure is consistent

57 with reduced cooperative unit sizes compared to the amorphous lysozyme and is consistent with a

58 reduction in the $\mathrm{T}_{\mathrm{m}}$ of the crystalline form. Evidence was obtained that milling also induced

59 denaturation in the solid-state, with the denatured lysozyme showing no thermal transition. The

60 denaturation of the crystalline lysozyme occurred mainly through its amorphous form.

61 Interestingly, the mechanical denaturation of lysozyme did not affect its biological activity on

62 dissolution. Lysozyme crystals on drying did not become amorphous, while milling-time played a

63 crucial role in the crystalline-amorphous-denatured transformations of lysozyme crystals. DSC is

64 shown to be a key tool to monitor quantitatively these transformations.

65 KEYWORDS:

66 Crystalline-amorphous-denatured transformations; Differential scanning calorimetry; FT-Raman;

67 Lysozyme crystals; Milling; X-ray powder diffraction.

68 


\section{Introduction}

Lysozymes are a group of enzymes defined as 1,4- $\beta$-N-acetylmuramidases cleaving the

72 glycosidic bond in the bacterial peptidoglycan. Hen egg white lysozyme (HEWL) is a single chain

73 polypeptide of 129 amino acids cross-linked with four disulfide bridges resulting in a molecular

74 weight of 14307 Da [1]. HEWL has the ability to lyse bacteria, and therefore it has particular

75 interest for application in food and pharmaceutical products [2]. Previous researchers assured its

76 potent antimicrobial efficiency [3] and its safety [4]. Also, other research has resulted in improved

77 intranasal absorption and delivery [5] and lung delivery [6].

Zhou et al. [7] made lysozyme containing mats and they verified its excellent antibacterial

79 activity against Escherichia coli and Staphylococcus aureus, and therefore, these mats have

80 promising uses in antimicrobial packing, tissue engineering, and wound dressing. Sax and Winter

81 [8] prepared sustained release lysozyme containing implants using hot melt extrusion. Schlocker

82 et al. [9] used milling to prepare protein-loaded microparticles in industrial quantities. Milling has

83 also been used to prepare protein particles suitable for pulmonary delivery [10]. However, milling

84 and other pharmaceutical processes (e.g., drying, mixing) may produce uncontrollable variation of

85 protein solid states (i.e., crystal structure and crystal habit) and also loss of protein activity [11].

86 Different lyophilized solid forms of proteins have been shown to produce different dissolution

87 rates for reconstitution [12]. The stability of crystalline lysozyme has been shown to be greater

88 than that of the amorphous form $[13,14]$. Therefore, it is essential to monitor the solid state

89 transformations of lysozyme during pharmaceutical processes.

90 Differential scanning calorimetry (DSC) is a well-established and widely used technique

91 to monitor solid state transformations. However, the thermal transitions of lysozyme, in common 
92 with other proteins, are usually characterized in the solution state, and often using a high-

93 sensitivity differential scanning calorimeter (HSDSC), which is capable of detecting the small

94 changes in enthalpy that arise when proteins unfold within their solutions [15]. Modulated

95 temperature differential scanning calorimetry [16] and thermally stimulated depolarized current

96 [17] have been tested as alternatives. However, the thermal transitions in the solution state cannot

97 differentiate the different solid forms. Therefore, researchers have studied the thermal transitions

98 of lysozyme in solid state using conventional solid-state DSC. However, their results did not

99 recognize the discrepancy between the thermal behaviours of the amorphous and crystalline

100 lysozyme powders [13,14,18,19].

101 There is a renewed interest in lysozyme, and its solid state form can have a significant

102 effect on dissolution and stability. We wished to explore how pre-treatment of lysozyme crystals

103 affected thermal behaviour, in an attempt to use thermal profiles as a fingerprinting indicator of

104 prior treatment. In this study, we prepare lysozyme crystals to be dried and/or milled, and 105 appropriate mixtures of the treated forms were prepared. Our aim is to use DSC to monitor the 106 potential solid state transformations of lysozyme during the treatment processes. We use Powder 107 X-ray diffraction (PXRD), FT-Raman, and enzymatic assay for reference. To our knowledge this 108 is the first application of DSC for the quantitative detection of crystalline, amorphous and 109 denatured lysozyme forms.

\section{2. Materials and methods}

112

\section{2.1. Materials}


Hen egg-white lysozyme (HEWL) (purity; 95\%) (Biozyme Laboratories, UK),

116 Micrococcus lysodeikticus (Sigma-Aldrich), sodium chloride (NaCl) (99.5\%) (Sigma-Aldrich) and

117 sodium acetate anhydrous (purity; 98\%) (BDH Chemicals Ltd., Poole, UK) were purchased as

118 indicated. The purchased lysozyme sample was considered to be unprocessed lysozyme. Water

119 was deionised and double distilled.

120

121 2.2. Sample Preparation

122

123

\subsubsection{Preparation lysozyme crystals using batch crystallization method}

124

125

One litre of a solution of lysozyme $4 \% \mathrm{w} / \mathrm{v}$ in sodium acetate buffer (pH 4.6; $0.1 \mathrm{M}$ ) and

126 one litre of a solution of sodium chloride $10 \% \mathrm{w} / \mathrm{v}$ in the same buffer were separately passed

127 through a 0.2 micron filter and then mixed in a glass container. The produced solution contained $1282 \% \mathrm{w} / \mathrm{v}$ lysozyme and 5\% w/v NaCl. This solution was then sealed and kept for ten days at $20{ }^{\circ} \mathrm{C}$.

129 Crystals formed were collected by filtration. Adsorbed water was removed by air drying (5 h).

130 These procedures were used to prepare lysozyme crystals by a batch crystallisation method [13].

131

132 2.2.2. Preparation of dried lysozyme crystals

133

134

A glass column of dimensions $2 \mathrm{~m}$ (three loops) $\times 6 \mathrm{~mm}$ (outer diameter) $\times 4 \mathrm{~mm}$ (inner 135 diameter), was packed with lysozyme crystals. Anhydrous nitrogen gas was passed through the 136 packed column at a flow rate of $10 \mathrm{ml} / \mathrm{min}, 30^{\circ} \mathrm{C}$ and zero relative humidity for 10 days. 


\subsubsection{Preparation of milled dried lysozyme powders}

Milling was achieved by rotating a marble pestle over the powder within a marble mortar

141 at $\sim 45$ cycles per minute (cpm). Milling times of 3, 10, 20, 30, 45, and 60 min were used to produce

142 different samples of milled dried crystals, named 3M, 10M, 20M, 30M, 45M, and 60M,

143 respectively. Another two batches of 3M,10M, 20M and 60M were also prepared for reference.

145 2.2.4. Preparation of amorphous lysozyme powders with different salt content

Precipitated samples were also prepared to explain the effect of $\mathrm{NaCl}$ on thermal behaviour

148 of lysozyme particles. These amorphous samples were prepared using the same principle of batch

149 crystallization method. Hence solutions containing $2 \% \mathrm{w} / \mathrm{v}$ lysozyme plus different amount of

$150 \mathrm{NaCl}(0,0.096,0.16$, and $0.8 \% \mathrm{w} / \mathrm{v})$ in deionised water were dried under vacuum at a temperature

$15130{ }^{\circ} \mathrm{C}$ for two days to produce lysozyme powders theoretically containing $0,24,40$ and $200 \mathrm{NaCl}$

152 molecules for each lysozyme molecule, respectively. These four lysozyme samples were named

153 P0, P24, P40, and P200, respectively, and their amorphous nature was confirmed by XRPD.

\subsubsection{Preparation of lysozyme mixtures from two different samples}

Unprocessed lysozyme and the 3M sample were mixed at different ratios (w/w) of 3:7, 5:5, and then in a small plastic bag for 10 min to ensure their homogeneity. 
A Zeiss Axioplan2 polarizing microscope (Carl Zeiss Vision GmbH; Hallbergmoos, 164 Germany) was used to visualize the samples. The accompanying software (Axio Vision 4.2) was 165 then used to determine the projected area diameters of the powders.

1707 Perkin Elmer Ltd., Beaconsfield, UK). Samples of 3-10 mg were heated from $30{ }^{\circ} \mathrm{C}$ to $210{ }^{\circ} \mathrm{C}$

171 at a scan rate of $10^{\circ} \mathrm{C} / \mathrm{min}$ in aluminium pan under nitrogen flow at $20 \mathrm{ml} / \mathrm{min}$. Each sample was

172 analysed in triplicate. The decrease in the weight before decomposition was calculated and was

173 considered as water content. TGA results were validated by re-analyzing the water content of some 174 samples using Karl Fischer Titration (KFT) (701 KF Titrino with 703 Ti stand, Metrohm, 175 Switzerland). Using TGA instead of KFT is that only a few mg is enough for TGA. 
$1832-10^{\circ}(2 \theta)$, with a step size of $0.001^{\circ}$ and a count time of 3 s per step. The sample stage was spun

184 at $30 \mathrm{rpm}$. The instrument was calibrated prior to use, using a silicon standard.

185

186

2.6. Differential scanning calorimetry (DSC)

187

188

Differential scanning calorimetry (DSC) thermograms were obtained using a Perkin-Elmer

189 Series 7 DSC (Perkin-Elmer Ltd., Beaconsfield, UK). Samples (4-7 mg) were sealed in aluminium

190 pans. The escape of water was facilitated by placing a pinhole in the lid prior to sealing. The

191 samples were equilibrated at $30^{\circ} \mathrm{C}$ and heated to $210^{\circ} \mathrm{C}$ at a scan rate of $10^{\circ} \mathrm{C} / \mathrm{min}$ under a flow

192 of anhydrous nitrogen $(20 \mathrm{ml} / \mathrm{min})$. Each sample was analysed in triplicate. The temperature axis

193 and cell constant of the DSC cell were calibrated with indium (10 mg, $99.999 \%$ pure, melting

194 point $156.60{ }^{\circ} \mathrm{C}$, and heat of fusion $28.40 \mathrm{~J} / \mathrm{g}$ ).

195

196

2.6.1. Evaluation of microcalorimetric data

197

198

$\mathrm{T}_{\mathrm{m}}$ and calorimetric transition enthalpies $\left(\Delta H_{C a l}\right)$ were measured by DSC, and then the

199 cooperative unit size ( $\left.n^{\prime}\right)$ was calculated after baseline correction using Eq. (1):

200

$$
n^{\prime}=\Delta H_{v H} / \Delta H_{C a l}
$$

201 where $\Delta H_{v H}$ is the corresponding van't Hoff enthalpy of the unfolding. Bammel et al. [20]

202 indicated that $\Delta H_{v H}$ can be obtained from:

203

$$
\Delta H_{v H}=4 R T_{m}^{2} \Delta C_{p}(\max ) / \Delta H_{C a l}
$$

204 where $R$ is the universal gas constant $\left(8.314 \times 10^{-3} \mathrm{~kJ} \mathrm{~K}^{-1} \mathrm{~mol}^{-1}\right), \Delta C_{p}(\max )$ is the maximum heat 205 capacity and it is calculated from: 


\subsection{FT-Raman spectroscopy}

FT-Raman spectra of samples were recorded with a Bruker IFS66 optics system using a

211 Bruker FRA 106 Raman module. The excitation source was an Nd: YAG laser operating at 1064

$212 \mathrm{~nm}$ and a laser power of $50 \mathrm{~mW}$ was used. The FT-Raman module is equipped with a liquid

213 nitrogen cooled germanium diode detector with an extended spectrum band width covering the

214 wave number range $1800-450 \mathrm{~cm}^{-1}$. Samples were placed in stainless steel sample cups and

215 scanned 200 times with the resolution set at $8 \mathrm{~cm}^{-1}$. The observed band wave numbers were

216 calibrated against the internal laser frequency and are correct to better than $\pm 1 \mathrm{~cm}^{-1}$. The spectra

217 were corrected for instrument response. The experiments were run at a controlled room 218 temperature of $20 \pm 1^{\circ} \mathrm{C}$.

219

220 2.8. Enzymatic assay

221

222 Lysozyme catalyzes the hydrolysis of $\beta$-1,4-glycosidic linkages of cell-wall 223 mucopolysaccharides [18]. This principle was used to measure the activity of lysozyme as follows. $22430 \mu \mathrm{l}$ of lysozyme solution $0.05 \%$ in phosphate buffer $(\mathrm{pH}=5.2 ; 10 \mathrm{mM})$ was added to $2.97 \mathrm{ml}$ 225 substrate bacterial suspension $0.025 \%$ of Micrococcus lysodeikticus in phosphate buffer $(\mathrm{pH}=$ 226 6.24; 66mM). The decrease in the absorption at $450 \mathrm{~nm}$ was monitored by using a UV-Vis 227 spectrophotometer (Pu 8700, Philips, UK). The activity was determined by measuring the decrease 228 in the substrate bacterial suspension concentration with time. Hence the slope of the reduction in 
229 the light absorption at $450 \mathrm{~nm}$ against the time of $3 \mathrm{~min}$, starting when the protein solutions were

230 mixed with the substrate bacterial suspension, was considered to be the indicator of the activity

231 [21]. The measurements were performed in controlled temperature room at $20{ }^{\circ} \mathrm{C}$ to avoid

232 fluctuation of lysozyme activity. The concentrations of the protein solutions had been determined

233 prior to the activity tests using Eq. (4).

$$
\text { [Protein }]=A b s_{280 n m} / E_{280 n m}
$$

235 where [protein] is the concentration of protein in the tested solution $\mathrm{w} / \mathrm{v} \%, A b \mathrm{~s}_{280 \mathrm{~nm}}$ is the

236 absorption of the tested protein solution at $280 \mathrm{~nm}, E_{280 \mathrm{~nm}}$ is the absorption of protein standard

237 solution with concentration $0.05 \mathrm{w} / \mathrm{v} \%$. The concentrations of the solutions were diluted to be 238 about $0.05 \% \mathrm{w} / \mathrm{v}$ so as to give absorption of less than 0.8 . The activities of all samples were 239 measured relative to that of a corresponding fresh sample, which was considered as the standard 240 solution.

\section{3. Results and discussion}

245 3.1. Microscopy

Fig. S1 shows the photomicrograph of a lysozyme crystal. The anisotropic crystals 248 exhibited a birefringence phenomenon when viewed under a polarizing microscope. The elongated 249 prism-like crystals were in general of a projected area diameter of 1200 $\mu \mathrm{m}$ (Fig. S1). Their shape 
250 was consistent with their preparation temperature, which was $20^{\circ} \mathrm{C}$. The crystal shape of lysozyme

251 is known to be affected by temperature, and a temperature of $\sim 20^{\circ} \mathrm{C}$ usually results in elongated

252 prism-like crystals [22]. Samples 3M, 10M, 20M, and 30M had diameters of 80 $\mu \mathrm{m}$ (Fig. S2), 7

$253 \mu \mathrm{m}$ (Fig. S3), 2.5 $\mu \mathrm{m}$ (Fig. S4), and less than $1 \mu \mathrm{m}$ (Fig. S5), respectively.

254

255 3.2. Thermogravimetric analysis (TGA)

256

The results of TGA analysis were used to estimate the water content of the crystal forms.

258 The thermograms (Fig. 1) indicate that on drying using the conditions described above, the water

259 content decreased from $17.3 \pm 1.0 \% \mathrm{w} / \mathrm{w}$ to $2.6 \pm 0.3 \% \mathrm{w} / \mathrm{w}$. The obtained values of water content

260 in protein powders using TGA were previously shown to be consistent with Karl Fischer titration 261 data [13].

262

263

3.3. X-ray powder diffraction (XRPD)

264

265

The diffractogram presented in Fig. 2A shows an absence of diffraction peaks for the unprocessed lysozyme powder indicating that it was amorphous. However, in Fig. 2B diffraction

267 peaks for the lysozyme crystals at $2 \theta$ angles less than $8^{\circ}$ are present. Proteins are large molecules 268 and are crystallized typically in unit cells having high d values, and so according to Bragg's law, 269 lysozyme crystals are expected to diffract $x$-ray at low $2 \theta$ angles.

$270 \quad$ Because lysozyme crystals exist in different forms, the CMPR program (Version 1.32) [23]

271 was employed for phase identification. The observed PXRD peaks of the crystals at $2.82^{\circ}, 3.56^{\circ}$, $2724.47^{\circ}, 5.21^{\circ}, 6.09^{\circ}$, and $6.97^{\circ}$ (Fig. 2B) fitted the faces $(H, K, L)\{(1,1,1),(3,1,0),(4,0,0),(4,1,1)$, 
$273(4,3,1),(5,3,1)\}$ of the tetragonal form of lysozyme with parameters $A=78.54, B=78.54$ and $274 \mathrm{C}=37.77, \alpha=\beta=\gamma=90^{\circ}$ taken from protein data bank reference number 193L [24].

275 Dried lysozyme crystals were also characterised using PXRD and data indicated that the 276 degree of crystallinity was predominantly maintained. The fact that the intensity of the XRPD 277 peaks, which did not notably change (Fig. 2C), was evidence to this effect. Minor up shifting in 278 the diffracted peaks after drying was noticed. This can be due to shrinkage of the unit cell to lower 279 d values upon dehydration. The cell volume of tetragonal lysozyme crystals shrunk under the effect 280 of pressure without a loss in its diffraction property [25]. Our XRPD finding agrees with previous 281 results. For example, both monoclinic and triclinic crystals of HEWL have been shown to maintain 282 their ability to diffract X-rays after dehydration [26] and [27], respectively. However, it contradicts 283 some previous low frequency Raman spectra results, which showed that tetragonal lysozyme 284 crystals resulted in crystallinity loss and conversion into an isotropic material (amorphous) after 285 drying from $\sim 33.5 \% \mathrm{w} / \mathrm{w}$ to $\sim 9 \% \mathrm{w} / \mathrm{w}$ water content by equilibrating at $\sim 30 \%$ r.h. $[28,29]$. In 286 287 collapses and loses its packing structure, some crystals survive their crystallinity upon dehydration 288 [26]. The findings of the present study would suggest that the conditions of the drying process 289 would play an important part as to whether crystallinity is maintained. Thus if protein crystals are 290 to be used as a drug delivery vehicle after bulk crystallisation then the subsequent milling and 291 drying conditions will require close control and monitoring to obtain consistent results.

292 Milling of the dried crystals did produce a loss in crystallinity. XRPD was able to follow 293 the loss of crystallinity of dried lysozyme crystals with comminution time. In case of 3M, the three 294 minutes of milling did not induce crystallinity loss (Fig. 2D) as indicated by PXRD. However, the 295 intensity of the diffracted peaks of sample 10M decreased (Fig. 2E). This indicates that lysozyme 
crystals became partially disordered after only 10 minutes of milling. Fig. $2 \mathrm{~F}$ shows that 20

297 minutes of milling was sufficient to produce a diffractogram with no clear peaks for the $20 \mathrm{M}$

298 sample, and so its XRPD spectrum became similar to that of the amorphous lysozyme

299 (unprocessed) (Fig. 2A) which is consistent with transformation to the amorphous state.

301 3.4. Differential scanning calorimetry (DSC)

302

Lysozyme DSC thermograms, in the solid state, typically show two endothermic peaks.

304 The broad peak ranging from $\sim 30$ to $\sim 140{ }^{\circ} \mathrm{C}$ is due to water removal, and its area depends on the

305 water residue in the samples. The second peak at $\sim 20{ }^{\circ} \mathrm{C}$, and its peak maximum was considered

306 to reflect the apparent denaturation temperature $\left(T_{m}\right)[13,14,18,19,30]$. Fig. 3A shows a typical

307 lysozyme thermogram demonstrating the presence of peaks at similar positions to those mentioned

308 above. Thermograms for all other samples show a consistent water removal peak. However, the

309 position and magnitude of $\mathrm{T}_{\mathrm{m}}$ peak was found to depend on the solid state form of the lysozyme

310 powder. The differences observed from DSC analysis align with the differences between the states

311 previously observed by XRPD (Fig. 2). Amorphous lysozyme obtained as received (unprocessed

312 lysozyme) thermally peaked at a $\mathrm{T}_{\mathrm{m}}$ of about $\sim 201{ }^{\circ} \mathrm{C}$ (Fig. 3A), while samples of crystalline

313 lysozyme (crystals, dried crystals, or the minimally milled $3 \mathrm{M}$ sample) gave a lower $\mathrm{T}_{\mathrm{m}}$ of about

$314 \sim 187^{\circ} \mathrm{C}$ (Figs 4B, 4C and 4D). Evidence that the 10M sample was transformed partially to an

315 amorphous form was apparent from inspection of the DSC thermal scan since it contained two

316 distinct $\mathrm{T}_{\mathrm{m}}$ 's consistent with amorphous and crystalline lysozyme forms respectively at separate

$317 \mathrm{~T}_{\mathrm{m}}$ of $\sim 187$ and $\sim 201{ }^{\circ} \mathrm{C}$ (Fig. 3E). Similar to the XPRD evidence above, DSC data suggested that 
318 further milling completed the amorphous transformation, with the $20 \mathrm{M}$ sample being amorphous, 319 and hence it only had the $\mathrm{T}_{\mathrm{m}}$ of an amorphous state at $\sim 201^{\circ} \mathrm{C}$ (Fig. 3F).

320 Close scrutiny of the thermograms showed that for sample 20M (amorphous lysozyme),

$321 \mathrm{~T}_{\mathrm{m}}$ was slightly decreased by only $\sim 1{ }^{\circ} \mathrm{C}$ compared to that of the other amorphous lysozyme

322 (unprocessed sample). However, this small difference was significant (t-Test: $\mathrm{P}<0.05$ ) (Table 1).

323 This minor reduction is likely to be due to the presence of $\mathrm{NaCl}$ content in the former sample. The

324 amount of $\mathrm{NaCl}$ in the lysozyme crystal is approximated to be $\sim 10 \mathrm{NaCl}$ molecules for each

325 lysozyme molecule. At the preparation $\mathrm{pH}$, each molecule of lysozyme needed $\sim 10 \mathrm{Cl}^{-}$ions of

$326 \mathrm{NaCl}$ to shield its positive charges, which induce the repulsion between lysozyme molecules. This

327 shielding by counter ions of the precipitant $(\mathrm{NaCl})$ is necessary to start nucleation and form crystals

328 in which these ions are trapped [31]. The precipitated samples which were precipitated with

329 different salt contents (P0, P24, P40, and P200) revealed a strong inverse relationship between salt

330 content and $T_{m}$ (correlation coefficient $r=-0.92$ ). The values of $T_{m}$ were 202.2 $\pm 0.3,200.3 \pm 0.5$,

331 198.2 \pm 0.5 , and 195.8 \pm 0.2 , respectively, and their DSC profiles and amorphous PXRD patterns are

332 provided in supplementary data (Fig. S6 and Fig. S7). Therefore, according to this correlation, the

333 presence of around $10 \mathrm{NaCl}$ molecules for each lysozyme molecule reduces $\mathrm{T}_{\mathrm{m}}$ by $\sim 1^{\circ} \mathrm{C}$.

334 The $\mathrm{T}_{\mathrm{m}}$ of a protein does not necessarily represent a solid-liquid transformation. Proteins

335 do not melt, but they change their molecular conformation from a native to denatured state at the

$336 \mathrm{~T}_{\mathrm{m}}$ which overcomes the attractive intra-molecular forces, which preserve their native state. In

337 solution state where lysozyme molecules are well separated from each other by water molecules,

338 the $\mathrm{T}_{\mathrm{m}}$ of lysozyme is $\sim 76{ }^{\circ} \mathrm{C}$ [32]. The cooperative unit $(n ')$ is typically thought to estimate the

339 lowest number of molecules which form an independently melting cluster of molecules within a

340 sample [33] and is used as an indicator of the degree of unfolding cooperativity of lysozyme [15]. 
341 In solution state, $n^{\prime}$ of lysozyme solutions ranges from 1 to 2 (i.e., 1.5) [34] Compared with the

342 solution state, $n^{\prime}$ of lysozyme in the dried amorphous form (e.g. unprocessed or 20M sample) was

343 estimated to increase from $\sim 1.5$ to $\sim 10.5$, and this is associated with the increase in $\mathrm{T}_{\mathrm{m}}$ from $\sim 76$

344 to $\sim 201^{\circ} \mathrm{C}$ (Table 1$)$.

345 We can postulate that when the cooperative unit increases, a higher temperature is needed 346 to unfold the lysozyme molecular aggregates, and that the larger the cooperative unit, the higher 347 the $\mathrm{T}_{\mathrm{m}}$. The $n^{\prime}$ of the crystalline form (e.g. crystals, dried crystals, 3M) was lower than those of the 348 amorphous form by $\sim 2.5$ unit (t-Test: $\mathrm{P}<0.05$ ) (Table 1). This explains the reduction in $\mathrm{T}_{\mathrm{m}}$ of the 349 crystalline form by $\sim 14{ }^{\circ} \mathrm{C}$ compared to the amorphous form. Although the unfolding of proteins 350 is an intra-molecular phenomenon rather than an inter-molecular phenomenon, the unfolding of a 351 molecule within a molecular aggregate is resisted by the steric hindrance and repulsion of the other 352 molecules in the unit.

353 Table 1 and Fig. 3 show that milling decreased the $\Delta H_{\text {Cal }}$ of the unfolding peak of the 354 crystalline form $\left(\Delta H_{C a l}^{C r}\right)$ with a corresponding increase in the $\Delta H_{\text {Cal }}$ of the unfolding peak of the 355 amorphous form $\left(\Delta H_{C a l}^{A m}\right)$. When $\Delta H_{C a l}^{C r}$ vanished, $\Delta H_{C a l}^{A m}$ reached a maximum of $105.9 \mathrm{~kJ}^{\mathrm{m}} \mathrm{mol}{ }^{-1}$ 356 (as in the case of $20 \mathrm{M}$ sample), which is lower than those of both the crystalline form (dried 357 crystals) and the amorphous form (unprocessed sample). Therefore, the complete crystalline358 amorphous transformation associated with slightly mechanical denaturation ( 17\%). The further 359 milling denatured gradually the amorphous form, as $\Delta H_{C a l}^{A m}$ decreased gradually by milling (i.e., $36030 \mathrm{M}$ and 45M samples). Prolonged milling of dried crystals produced thermal evidence of a loss 361 of unfolding due to the absence of a $T_{m}$ as in the case of 60M (Fig. 3I). Fig. 4 summarizes the 362 correlation between the milling time and the calorimetric unfolding enthalpies of the crystalline 363 and amorphous peaks. This observation coupled with the milling data discussed above is 
364 suggestive that milling initially induced a partial crystalline-amorphous transformation, followed 365 by a complete amorphization transformation, and then on subsequent prolonged milling produced 366 complete mechanical denaturation. Although a small part of lysozyme molecules denatured during

367 the crystalline-amorphous transformation, the mechanical denaturation of crystalline lysozyme 368 mainly goes through amorphous state. Similarly, the other two batches of 3M, 10M, 20M and 60M 369 verified the crystalline-amorphous-denatured transformations of lysozyme powders during milling 370 and the distinctive thermal behaviours of each form (Table 2).

\subsubsection{Quantitative analysis of lysozyme solid states by DSC}

Conventional DSC has been used to estimate the different solid phases in lactose powders.

375 The estimation depended on knowing the enthalpy of solid phase transformation for each form.

376 This DSC approach has been previously verified [35].

Applying the same approach to monitor the processing of the lysozyme powders, crystalline lysozyme (i.e. crystals) and amorphous lysozyme (i.e. unprocessed powder) produced 379 similar enthalpies (t-Test: $\mathrm{P}>0.05$ ), with an average of 125 and $134 \mathrm{~kJ}^{-\mathrm{mol}^{-1}}$, respectively. 380 Therefore, these values were considered as the enthalpy of the native solid lysozyme. We assume 381 that milled solid lysozyme powders would consist of mixtures of crystalline, amorphous and/or 382 denatured lysozyme. The percentages of crystalline form (Cr\%), amorphous form (Am\%), and 383 denatured form (De\%) in the lysozyme powders can be determined from:

$$
\mathrm{Cr} \%=\left(\Delta H_{\text {Cal }}^{\sim 187} / 125\right) \times 100
$$

$$
\operatorname{Am} \%=\left(\Delta H_{\text {Cal }}^{\sim 201} / 134\right) \times 100
$$

$$
\mathrm{De} \%=100-(\mathrm{Cr} \%+\mathrm{Am} \%)
$$


387 where $\Delta H_{\text {Cal }}^{\sim 187}$ and $\Delta H_{\text {Cal }}^{\sim 201}$ are the measured enthalpy $\left(\mathrm{kJ}^{2} \mathrm{~mol}^{-1}\right)$ of the unfolding peaks at $\mathrm{T}_{\mathrm{m}}$ of $388 \sim 187$ and $\sim 201^{\circ} \mathrm{C}$, respectively.

389 To test the quantitative hypothesis amorphous lysozyme (unprocessed sample) and 390 crystalline lysozyme (3M sample) were mixed at different ratios of 3:7, 5:5, and 7:3 and then they 391 analysed by DSC (same procedures). According to Eq. (5), (6) and (7), the amorphous sample 392 contains $100 \%$ native lysozyme, but the crystalline sample, which had $\Delta H_{\text {Cal }}^{\sim 187}=114.4 \mathrm{~kJ}^{1 . \mathrm{mol}^{-1}}$, 393 contains $91.5 \%$ native and $8.5 \%$ denature lysozyme. Therefore, the three mixtures of 394 unprocessed:3M (3:7, 5:5 and 7:3) should contain (27.4\%, 70.0\%, 2.6\%), (45.7\%, 50.0\%, 4.3\%) 395 and (64.0\%, 30.0\%, 6.0\%) of (Cr\%, Am\%, and De\%), respectively. These calculated crystalline, 396 amorphous and denatured percentages using the above equations were similar to the actual 397 percentages in the mixtures listed in Table 3. Fig. 5 shows the distinctive unfolding peaks of the 398 crystalline and amorphous forms of the mixtures.

\subsection{FT-Raman study}

401

Raman spectroscopy was used to compare the molecular conformation of crystalline (3M

403 sample), amorphous lysozyme (20M sample) and extensively milled (denatured) lysozyme (60M 404 sample) with dried lysozyme crystals. The band at $1447 \mathrm{~cm}^{-1}$ indicates the $\mathrm{CH}$ bending vibrations 405 of aliphatic side chains, and its intensity and position are unaffected by changes induced in protein 406 structure after dehydration or applying different stresses [36]. Therefore, it was used as internal 407 intensity standard to normalize Raman spectra before comparison (Fig. 6A).

408 Compared to the amorphous form of lysozyme (20M sample), the crystalline form (dried 409 crystals and 3M sample) showed greater intensity of the $v \mathrm{Ca}-\mathrm{C}-\mathrm{N}$ mode at $930 \mathrm{~cm}^{-1}$ (Fig. 6B), 
410 and produced a higher vibration mode of amide III ( $\mathrm{N}-\mathrm{H}$ in-plane bend + C-N stretch) at 1265

$411 \mathrm{~cm}^{-1}$ (Fig. 6C) and a lower and sharper vibration mode of amide I (C=O stretch) at $\sim 1660 \mathrm{~cm}^{-1}$

412 (Fig. 6D). The intensity of $v$ Ca-C-N mode at $930 \mathrm{~cm}^{-1}$ [37], upshifting of amide III (N-H in-plane

413 bend + C-N stretch) [38], and downshifting and sharpening of the line of amide I (C=O stretch) at

$414 \sim 1660 \mathrm{~cm}^{-1}[39]$ indicates a higher $\alpha$-helix content. This means that the crystalline form maintained

415 the $\alpha$-helix structure of native lysozyme more than the amorphous form. The native secondary

416 structure of lysozyme consists of three alpha helix regions extending 5-15, 24-34 and 88-96 amino

417 acid residues [24].

418 Rich $\alpha$-helix structures have a low tendency to aggregate compared to rich $\beta$-sheet

419 structures [15]. This possibly explains why the crystalline form had less tendency to thermally

420 unfold in lower $n^{\prime}$ compared to the amorphous form. Therefore, according to our above postulation,

421 the spectroscopic observation that the crystalline form contains more alpha helix may explain why

422 the crystalline lysozyme unfolded at lower $\mathrm{T}_{\mathrm{m}}$.

423 Comparison of the spectrum of the denatured lysozyme (sample 60M) with that of the

424 amorphous form shows that mechanical denaturation induced further reduction in the intensity of $425 v$ Ca-C-N mode at $930 \mathrm{~cm}^{-1}$ (Fig. 6B), which in turn implies a further reduction in $\alpha$-helix content. 426

427 3.6. Enzymatic assay

428 Interestingly, milled samples did not show a reduction in biological activity (ANOVA: P >

430 0.05) (Table 4). The ability of lysozyme to re-nature on dissolution is a possible explanation for 431 this finding. Indeed, previous research has shown the strong refolding ability of lysozyme upon 432 dissolution in aqueous media [40]. Likewise, despite significant loss of the Raman vibrations of 
433 lysozyme upon denaturation by $\gamma$-irradiation, the denatured lysozyme samples almost fully 434 recovered their biological activity on dissolution [39].

\section{Conclusions}

440 to lead to complex material properties of crystals in the solid state. Here we exemplify, using the 441 model drug lysozyme, the effects of processing lysozyme crystals and are able to show distinct 442 differences in the properties of the materials after processing which could be used in optimising 443 and controlling processes for the purposes of quality by design.

444 By drying lysozyme crystals using a controlled method we were able to evidence the 445 removal of water and maintain crystallinity. However, the size reduction of dried lysozyme crystals 446 by milling was shown to promote formation of an amorphous solid-state form. Raman 447 spectroscopy provided evidence that the amorphous form was then denatured in the solid state by 448 further milling. The milling time was the critical attribute determining the extent of the 449 transformations. DSC was successfully employed in monitoring the three different states of 450 lysozyme (namely crystalline, amorphous, and denatured) in the solid state. The DSC thermogram 451 of the crystalline lysozyme exhibited $\mathrm{T}_{\mathrm{m}}$ at $\sim 187^{\circ} \mathrm{C}$ which was lower than that of amorphous 452 lysozyme by $\sim 14{ }^{\circ} \mathrm{C}$. The mechanically denatured lysozyme did not provide a thermal unfolding 453 transition. The calorimetric enthalpies of the crystalline and amorphous peaks were used to analyze 454 quantitatively the three different states of lysozyme. XRPD data were consistent with the 455 crystallinity of lysozyme identified by DSC. Interpretation of the Raman data from the same 
456 samples is consistent with a crystalline form having a lower tendency to aggregate due to its greater

$457 \alpha$-helix rich structure compared to the amorphous form. Significantly, although the molecular 458 arrangement and molecular conformation of lysozyme changed during milling, its biological 459 activity did not decrease. Clearly, subtle changes in solid-state processing conditions of crystalline 460 lysozyme can bring about major changes in its solid-state properties. The effects of a wider range 461 of milling variables, including different mill types, on lysozyme solid-state transformations and 462 behaviour will be the subject of a future study.

\section{Acknowledgements}

466 acknowledges CARA (Zeid Al-Bayaty and Kate Robertson) for providing an academic fellowship. 


\section{References}

[1] W. Zhao, R. Yang, R. Lu, Y. Tang, W. Zhang, Investigation of the mechanisms of pulsed electric fields on inactivation of enzyme: lysozyme, J. Agric. Food Chem. 55 (2007) 98509858.

[2] E.A. Charter, G. Lagarde, Natural anti-microbial systems: Lysozyme and other proteins in eggs, in: C.A. Batt (Second Edition), Encyclopedia of Food Microbiology, Elsevier, Ltd., San Diego, 2014, pp. 936-940.

[3] M.I. Hoq, H.R. Ibrahim, Potent antimicrobial action of triclosan-lysozyme complex against skin pathogens mediated through drug-targeted delivery mechanism, Eur. J. Pharm. Sci. 42 (2011) 130-137.

[4] D. Cerven, G. DeGeorge, D. Bethell, 28-Day repeated dose oral toxicity of recombinant human apo-lactoferrin or recombinant human lysozyme in rats, Regul. Toxicol. Pharm. 51 (2008) 162167.

[5] H.J. Cho, P. Balakrishnan, S.J. Chung, C.K. Shim, D.D. Kim, Evaluation of protein stability and in vitro permeation of lyophilized polysaccharides-based microparticles for intranasal protein delivery, Int. J. Pharm. 416 (2011) 77-84.

[6] O.N. Ógáin, J. Li, L. Tajber, O.I. Corrigan, A.M. Healy, Particle engineering of materials for oral inhalation by dry powder inhalers. I-Particles of sugar excipients (trehalose and raffinose) for protein delivery, Int. J. Pharm. 405 (2011) 23-35.

[7] B. Zhou, Y. Li, H. Deng, Y. Hu, B. Li, Antibacterial multilayer films fabricated by layer-bylayer immobilizing lysozyme and gold nanoparticles on nanofibers, Colloids Surf. B Biointerfaces 116 (2014) 432-438.

[8] G. Sax, G. Winter, Mechanistic studies on the release of lysozyme from twin-screw extruded lipid implants, J. Control. Release 163 (2012) 187-194.

[9] W. Schlocker, S. Gschließer, A. Bernkop-Schnürch, Evaluation of the potential of air jet milling of solid protein-poly (acrylate) complexes for microparticle preparation, Eur. J. Pharm. Biopharm. 62 (2006) 260-266.

[10] H. Hoyer, W. Schlocker, K. Krum, A. Bernkop-Schnürch, Preparation and evaluation of microparticles from thiolated polymers via air jet milling, Eur. J. Pharm. Biopharm. 69 (2008) 476-485.

[11] J.H. Kwon, C.W. Kim, A novel insulin microcrystals preparation using a seed zone method, J. Cryst. Growth 263 (2004) 536-543.

[12] C. Müller, J. Ulrich, The dissolution phenomenon of lysozyme crystals, Cryst. Res. Technol. 47 (2012) 169-174.

[13] A.A. Elkordy, R.T. Forbes, B.W. Barry, Integrity of crystalline lysozyme exceeds that of a spray-dried form, Int. J. Pharm. 247 (2002) 79-90.

[14] A.A. Elkordy, R.T. Forbes, B.W. Barry, Stability of crystallised and spray-dried lysozyme, Int. J. Pharm. 278 (2004) 209-219.

[15] H. Liu, P. Yin, S. He, Z. Sun, Y. Tao, Y. Huang, H. Zhuang, G. Zhang, S. Wei, ATP-induced noncooperative thermal unfolding of hen lysozyme, Biochem. Biophys. Res. Commun. 397 (2010) 598-602.

[16] A. Badkar, P. Yohannes, A. Banga, Application of TZERO calibrated modulated temperature differential scanning calorimetry to characterize model protein formulations, Int. J. Pharm. 309 (2006) 146-156. 
[17] Y. Hirakura, H. Yamaguchi, M. Mizuno, H. Miyanishi, S. Ueda, S. Kitamura, Detection of lot-to-lot variations in the amorphous microstructure of lyophilized protein formulations International, Int. J. Pharm. 340 (2007) 34-41.

[18] R.R. Haj-Ahmad, A.A. Elkordy, C.S. Chaw, A. Moore, Compare and contrast the effects of surfactants (Pluronic ${ }^{\circledR} \mathrm{F}-127$ and Cremophor ${ }^{\circledR} \mathrm{EL}$ ) and sugars ( $\beta$-cyclodextrin and inulin) on properties of spray dried and crystallised lysozyme, Eur. J. Pharm. Sci. 49 (2013) 519-534.

[19] Z. Du, Y.X. Guan, S.J. Yao, Z.Q. Zhu, Supercritical fluid assisted atomization introduced by an enhanced mixer for micronization of lysozyme: Particle morphology, size and protein stability, Int. J. Pharm. 421 (2011) 258-268.

[20] B.P. Bammel, D.D. Hamilton, R.P. Haugland, H.P. Hopkins, J. Schuette, W. Szalecki, J.C. Smith, NMR, calorimetric, spin-label, and optical studies on a trifluoromethyl-substituted styryl molecular probe in dimyristoylphosphatidylcholine vesicles and multilamellar suspensions: a model for location of optical probes, BBA-Biomembranes 1024 (1990) 61-81.

[21] D. Shugar, Measurement of lysozyme activity and the ultraviolet inactivation of lysozyme, Biochim. Biophys. Acta 8 (1952) 302.

[22] J. Lu, X.J. Wang, C.B. Ching, Batch crystallization of soluble proteins: effect of precipitant, temperature and additive, Prog. Cryst. Growth Ch. 45 (2002) 201-217.

[23] B.H. Toby, CMPR - a powder diffraction toolkit, J. Appl. Crystallogr. 38 (2005) 1040-1041.

[24] M.C. Vaney, S. Maignan, M. RiesKautt, A. Ducruix, High resolution structure (1.33 angstrom) of a HEW lysozyme tetragonal crystal grown in the APCF apparatus: data and structural comparison with a crystal grown under microgravity from SpaceHab-01 mission, Acta Crystallogr. D Biol. Crystallogr. 52 (1996) 505-517.

[25] C. Charron, M.C. Robert, B. Capelle, A. Kadri, G. Jenner, R. Giegé, B. Lorber, X-ray diffraction properties of protein crystals prepared in agarose gel under hydrostatic pressure, $\mathrm{J}$. Cryst. Growth 245 (2002) 321-333.

[26] K. Harata, T. Akiba, Structural phase transition of monoclinic crystals of hen egg-white lysozyme, Acta Crystallogr. D Biol. Crystallogr. 62 (2006) 375-382.

[27] G.S. Kachalova, V.N. Morozov, T.Y. Morozova, E.T. Myachin, A.A. Vagin, B.V. Strokopytov, Y.V. Nekrasov, Comparison of structures of dry and wet hen egg-white lysozyme molecule at $1.8 \AA$ resolution, FEBS Lett. 284 (1991) 91-94.

[28] H. Urabe, Y. Sugawara, M. Ataka, A. Rupprecht, Low-frequency Raman spectra of lysozyme crystals and oriented DNA films: Dynamics of crystal water, Biophys. J. 74 (1998) 1533-1540.

[29] A.B. Kudryavtsev, G. Christopher, C.D. Smith, S.B. Mirov, W.M. Rosenblum, L.J. DeLucas, The effect of ordering of internal water in thaumatin and lysozyme crystals as revealed by Raman method, J. Cryst. Growth 219 (2000) 102-114.

[30] W.L. Hulse, R.T. Forbes, M.C. Bonner, M. Getrost, Do co-spray dried excipients offer better lysozyme stabilisation than single excipients?, Eur. J. Pharm. Sci. 33 (2008) 294-305.

[31] F. Rosenberger, Protein crystallization, J. Cryst. Growth 166 (1996) 40-54.

[32] A.A. Elkordy, R.T. Forbes, B.W. Barry, Study of protein conformational stability and integrity using calorimetry and FT-Raman spectroscopy correlated with enzymatic activity, Eur. J. Pharm. Sci. 33 (2008) 177-190.

[33] H. Lu, J.C. Wojtowicz, I.A. Butovich, Differential scanning calorimetric evaluation of human meibomian gland secretions and model lipid mixtures: Transition temperatures and cooperativity of melting, Chem. Phys. Lipids 170 (2013) 55-64. 
575 [34] N. Hassan, P.V. Verdes, J.M. Ruso, Assessment of interactions between four proteins and benzothiazole derivatives by DSC and CD, J. Chem. Thermodyn. 43 (2011) 399-404.

[35] W. Kaialy, G.P. Martin, M.D. Ticehurst, P. Royall, M.A. Mohammad, J. Murphy, A. Nokhodchi, Characterisation and deposition studies of recrystallised lactose from binary mixtures of ethanol/butanol for improved drug delivery from dry powder inhalers, AAPS J. 13 (2011) 30-43.

[36] T.J. Yu, J.L. Lippert, W.L. Peticolas, Laser Raman studies of conformational variations of poly-L-lysine, Biopolymers 12 (1973) 2161-2176.

[37] S. Ikeda, Heat-induced gelation of whey proteins observed by rheology, atomic force microscopy, and Raman scattering spectroscopy, Food Hydrocoll. 17 (2003) 399-406.

[38] E.C. Li-Chan, The applications of Raman spectroscopy in food science, Trends Food Sci. Tech. 7 (1996) 361-370.

[39] A. Torreggiani, M. Tamba, I. Manco, M.R. Faraone-Mennella, C. Ferreri, C. Chatgilialoglu, Radiation damage of lysozyme in a biomimetic model: some insights by Raman spectroscopy, J. Mol. Struct. 744 (2005) 767-773.

[40] C. Pérez-Rodriguez, N. Montano, K. Gonzalez, K. Griebenow, Stabilization of $\alpha-$ chymotrypsin at the $\mathrm{CH}_{2} \mathrm{Cl}_{2}$ /water interface and upon water-in-oil-in-water encapsulation in PLGA microspheres, J. Control. Release 89 (2003) 71-85.

593

594 